\title{
ANALISA KEKUATAN KOMPOSIT SANDWICH KARBON FIBER DENGAN CORE STYROFOAM SEBAGAI MATERIAL PADA MODEL PESAWAT TANPA AWAK (UJI TARIK \& UJI BENDING)
}

\author{
Dadang Setiyawan*, Sri Mulyo Bondan Respati dan Muhammad Dzulfikar \\ Jurusan Teknik Mesin Universitas Wahid Hasyim Semarang \\ Jl. Menoreh Tengah X/22 Sampangan Semarang 50236 \\ *Email: dadangasoyy@gmail.com
}

\begin{abstract}
Abstrak
Perkembangan teknologi di dunia kedirgantaraan semakin maju. Ketergantungan pada bahan buatan yang semakin tinggi menuntut terciptanya inovasi untuk mengembangkan material yang ringan namun tetap kuat tanpa meninggalkan aspek-aspek keselamatan. Perkembangan teknologi komposit makin serius di kembangkan. Salah satunya teknologi komposit dengan material serat inti busa (fiber foam core). Dalam penelitian ini variasi yang digunakan adalah lapisan bagian atas 1 sampai 3 lapisan. Pembuatan material menggunakan metode hand layup, spesimen menggunakan standar ASTM D 638 dan ASTM C 393. Pengujian tarik dan bending dengan pengulangan 3 kali. Dari hasil penelitian menunjukkan bahwa kekuatan tarik dan Bending tertinggi di dapat pada 3 lapisan atas komposit karbon fiber core styrofoam sebesar $605,38 \mathrm{~kg} / \mathrm{cm}^{2}$ dan untuk pengujian Bending 702,7 kg/ $\mathrm{cm}^{2}$.
\end{abstract}

Kata kunci: Komposit Karbon, Uji Bending, Uji Tarik

\section{PENDAHULUAN}

Perkembangan teknologi di dunia kedirgantaraan semakin maju dan ketergantungan pada bahan buatan yang semakin tinggi menuntut terciptanya inovasi untuk mengembangkan material yang ringan namun tetap kuat tanpa meninggalkan aspek-aspek keselamatan untuk terciptanya mutu kehidupan yang lebih baik. Perkembangan teknologi komposit makin serius di kembangkan. Salah satunya teknologi komposit dengan material serat inti busa (fiber foam core).

Sifat busa yang ringan merupakan faktor pendukung penggunaan material ini. Salah satu busa yang menjadi objek penelitian adalah busa jenis polyfoam atau biasa dikenal dengan depron. Secara umum polyfoam digunakan untuk tempelan majalah dinding. Sifat busa yang ringan merupakan faktor pendukung penggunaan material ini. Salah satu busa yang menjadi objek penelitian adalah busa jenis polyfoam atau biasa dikenal dengan depron. Secara umum polyfoam digunakan untuk tempelan majalah dinding. Polyfoam dapat juga dipakai sebagai salah satu bahan untuk pesawat tanpa awak (Nukhil and Nayak, 2014)

Komposit sandwich dibuat dengan tujuan untuk efisiensi berat yang optimal, namun mempunyai kekakuan dan kekuatan yang tinggi. Banyak variasi definisi dari komposit Sandwich, tetapi faktor utama dari material tersebut adalah core yang ringan sehingga memperkecil berat jenis dari material tersebut serta kekuatan lapisan skin yang memberikan kekuatan pada komposit sandwich (Wijoyo, 2014).

Serat karbon merupakan salah satu material yang cocok untuk komposisi komposit sandwich dengan inti busa di dalamnya. Serat karbon memiliki berat yang ringan serta ketangguhan yang dapat diandalkan. Kekuatan komposit sandwich biasanya tergantung pada jumlah lamina dan inti (core) pada komposisi komposit tersebut. Hal ini bertujuan untuk mendapatkan karakteristik serta kekuatan bahan yang di inginkan. Core pada komposit sandwich haruslah seringan mungkin untuk mendapatkan berat jenis yang ringan dari komposit sandwich. (Wijoyo, 2014)

Komposit sandwich untuk dapat digunakan harus diuji kekuatannya dalam pengujian kekuatan ini diperlukan pengujian tarik dan Bending (Hariyanto, 2007)

Dari uraian di atas, maka penggunaan styrofoam sebagai bahan core pada komposit sandwich merupakan solusi kreatif untuk mendukung perkembangan teknologi komposit sandwich yang ramah lingkungan.

\section{Pesawat Tanpa Awak}

UAV adalah pesawat tanpa awak (tanpa pilot). UAV dikendalikan tanpa awak (unmanned system), yaitu sebuah sistem elektromekanik yang dapat melakukan misi-misi 
terprogram . Bentuk pesawat tanpa awak dapat dilihat pada Gambar 1.

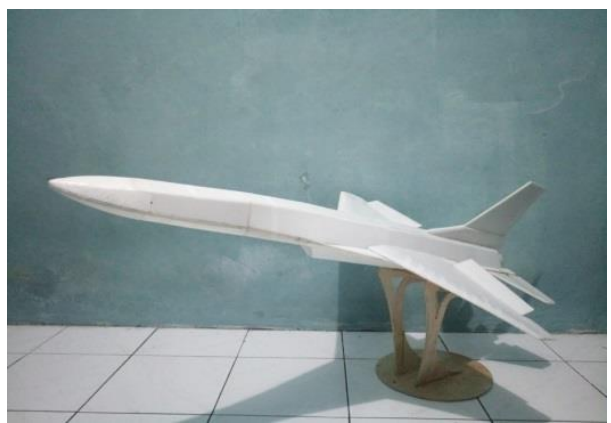

Gambar 1. Pesawat tanpa awak (unmanned aerial vehicle)

Tujuan dari penelitian ini adalah mencari bahan yang ringan tetapi mempunyai kekuatan yang memenuhi standar pesawat tanpa awak.

\section{METODE PENELITIAN}

Bahan

\section{- Styrofoam}

Styrofoam atau plastik busa merupakan salah satu jenis plastik dari sekian banyak bahan lainnya. Styrofoam lazim digunakan sebagai bahan pelindung dan penahan getaran barangbarang yang fragile, seperti elektronik.

\section{- Serat Karbon}

Secara morfologi serat karbon ada dalam berbagai bentuk, bubuk karbon aktif, pelumas padat karbon seperti gelas hitam yang sangat keras (Surdia dan Saito, 2000: 371). Jenis dan penggunaan karbon sangat luas. Sekarang sudah ada produksi masa dari serat karbon yang elastis dan dengan sifatnya yang ringan bahan ini memberikan harapan pada berbagai penggunaan. Karbon fiber merupakan material komposit yang sangat kuat, ringan, dan mahal. Serat karbon yang digunakan sudah berbentuk lembaran dari serat karbon yang di anyam.

Kedua bahan di atas disusun dibuat komposit sandwich.

\section{- Komposit Sandwich}

Komposit adalah material yang terdiri dari dua bahan yang mempunyai perbedaan sifat yang kemudian di gabungkan sehingga memiliki sifat material yang kita inginkan. Komposit sandwich adalah material yang terdiri dari 2 material atau lebih yang berupa skin dan core pada bagian intinya. Bentuk komposit sandwich dapat dilihat pada Gambar 2

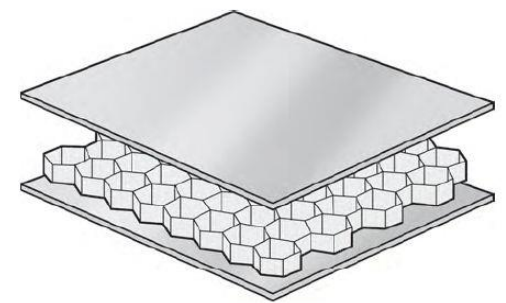

Gambar 2. Komposit Sandwich (Venkata, 2005)

Pembuatan komposit sandwich ini menggunakan Styrofoam dan serat karbon ini dilekatkan dengan lem. Setelah melekat dibuat spesimen uji densitas, uji tarik, uji Bending.

\section{Uji Densitas}

Uji Densitas adalah uji untuk mengetahui berat spesimen dibagi satuan volume (Respati dkk., 2017). Hasil uji densitas ini dipakai untuk memperkirakan seberapa berat jika dijadikan pesawat tanpa awak.

\section{Gaya Angkat Pada Pesawat}

Sayap adalah salah satu komponen pesawat yang menghasilkan sebagian besar gaya angkat. Pada sayap pesawat terbang mempunyai penampang sayap yang disebut dengan airfoil. Pergerakan airfoil ke depan membelah udara sehingga mengalir di bagian atas dan bawah airfoil. Perbedaan kecepatan aliran udara bagian atas dan bawah airfoil menimbulkan perbedaan tekanan pada penampang airfoil sehingga terjadi gaya angkat (Lennon, 1996). Ilustrasi dari Gaya angkat dapat dilihat pada Gambar 3.

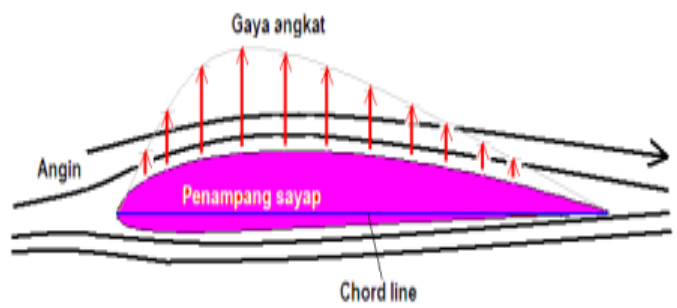

Gambar 3. Laju aliran udara pada penampang airfoil

Gaya angkat ini dipengaruhi oleh sudut serang. Pengaruhnya sudut serang terhadap koefisien gaya angkat dapat dilihat pada Gambar 4. Besarnya gaya angkat adalah:

$\mathrm{L}=1 / 2 \cdot \rho \cdot \mathrm{V}^{2} \cdot \mathrm{A} \cdot \mathrm{CL}$

Dimana:

$$
\begin{array}{ll}
\mathrm{L} & =\text { Gaya Angkat }(\mathrm{N}) \\
\rho & =\text { Densitas udara }\left(\mathrm{kg} / \mathrm{m}^{3}\right)
\end{array}
$$


$\mathrm{CL}=$ Coefisien Lift

$\mathrm{V}=$ Kecepatan $(\mathrm{m} / \mathrm{s})$

A $\quad=$ Luas Sayap $\left(\mathrm{m}^{2}\right)$

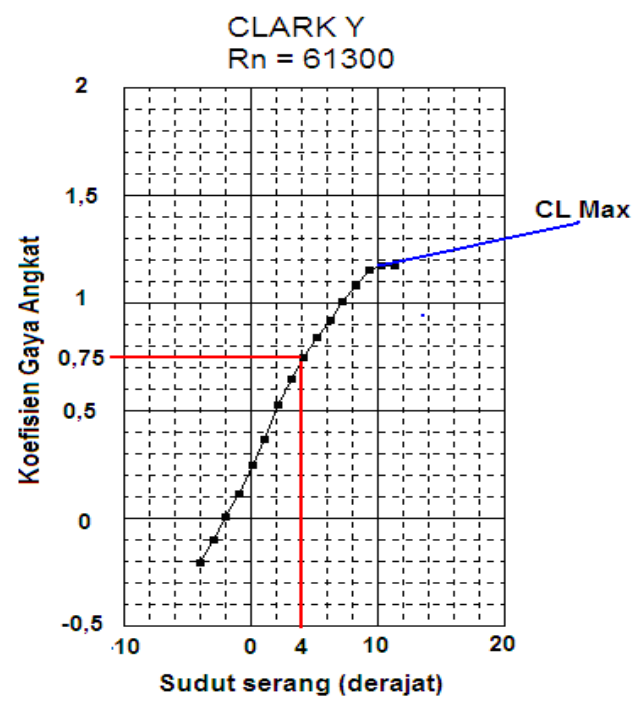

Gambar 4. Hubungan gaya angkat terhadap sudut serang (Lennon, 1996)

\section{Pengujian Tarik}

Pengujian tarik bertujuan untuk mengetahui pembebanan maksimum material pada saat pengujian tarik (Davis dkk., 1955) ilustrasi penarikan dapat dilihat pada Gambar 4

$\sigma=\frac{P}{A 0}$

$\varepsilon=\frac{\Delta L}{L 0}=\frac{L-L 0}{L 0}$

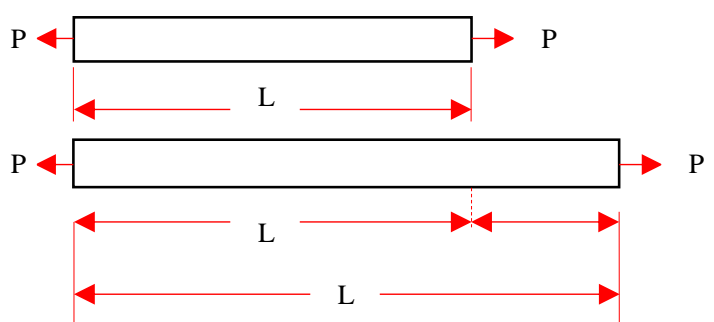

Gambar 5. Benda kerja bertambah panjang $\Delta L$ ketika diberi beban $P$ (Irwanto, 2014)

\section{Pengujian Bending}

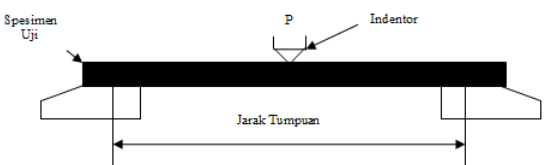

Gambar 6 Pemasangan benda uji Bending

(ASTM, 2003)
Untuk mengetahui Tegangan Bending suatu material dapat dilakukan dengan pengujian Bending terhadap material komposit tersebut. Sehingga kekuatan Bending dapat dirumuskan sebagai berikut:

$\sigma_{b}=\frac{3 P L}{2 b . t^{2}}$

Dimana: $\sigma_{\mathrm{b}}=$ Tegangan Tekuk (Mpa)

$\mathrm{P}=$ Beban $(\mathrm{N})$

$\mathrm{L}=$ Panjang Span $(\mathrm{mm})$

$\mathrm{b}=\operatorname{Lebar}(\mathrm{mm})$

$\mathrm{t}=$ Tebal $(\mathrm{mm})$

\section{HASIL DAN PEMBAHASAN}

Pengujian massa menggunakan timbangan digital dengan dimensi panjang $\mathrm{x}$ lebar x tinggi adalah $18.7 \mathrm{~cm}$ x $18.7 \mathrm{~cm}$ x tebal pada masing-masing spesimen yaitu $0,35 \mathrm{~cm}$, $0,38 \mathrm{~cm}, 0,41 \mathrm{~cm}$. Untuk lebih jelasnya bisa dilihat pada Tabel 1 adalah rata-rata dari volume dan berat.

Tabel 1. Volume dan Berat Spesimen

\begin{tabular}{llll}
\hline Lapisan & $\begin{array}{l}\text { Luas } \\
\left(\mathbf{c m}^{\mathbf{2}}\right)\end{array}$ & $\begin{array}{l}\text { Volume } \\
\left.\mathbf{( c m}^{\mathbf{3}}\right)\end{array}$ & $\begin{array}{l}\text { Massa } \\
(\mathbf{g r a m})\end{array}$ \\
\hline 1 lapisan & 122 & 122 & 52,86 \\
2 lapisan & 132 & 133 & 53,31 \\
3 lapisan & 143 & 143 & 62,35 \\
\hline
\end{tabular}

Sedangkan untuk berat jenisnya dapat dihitung dari data Tabel 1. Hasil perhitungan berat jenis disajikan pada Tabel 2 .

Tabel 2. Berat Jenis

\begin{tabular}{ll}
\hline Lapisan & $\begin{array}{l}\text { Berat Jenis } \\
\left(\mathbf{g} / \mathbf{c m}^{\mathbf{3}}\right)\end{array}$ \\
\hline 1 lapisan & 0,38 \\
2 lapisan & 0,40 \\
3 lapisan & 0,43 \\
\hline
\end{tabular}

Uji Tarik

Pengujian tarik di lakukan di Laboratorium Pengujian Bahan UNWAHAS. Pada penelitian "Analisa Kekuatan Komposit sandwich Karbon fiber dengan Core Styrofoam Sebagai Material Pada Pesawat tanpa Awak" ini didapatkan data yang diisikan pada Tabel 3 .

Tabel 3. Rata-rata Tegangan Tarik

\begin{tabular}{llll}
\hline Lapisan & $\begin{array}{l}\text { Tegangan } \\
\left(\mathbf{k g} / \mathbf{c m}^{2}\right)\end{array}$ & $\begin{array}{l}\text { Lo } \\
(\mathbf{c m})\end{array}$ & $\begin{array}{l}\Delta \mathbf{L} \\
(\mathbf{c m})\end{array}$ \\
\hline 1 Lapisan & 463 & 16,55 & 0,20 \\
2 Lapisan & 540 & 16,65 & 0,15 \\
3 Lapisan & 605 & 16,60 & 0,10 \\
\hline
\end{tabular}


Dari Tabel 3 dapat dibuat diagram yang disajikan pada Gambar 7.

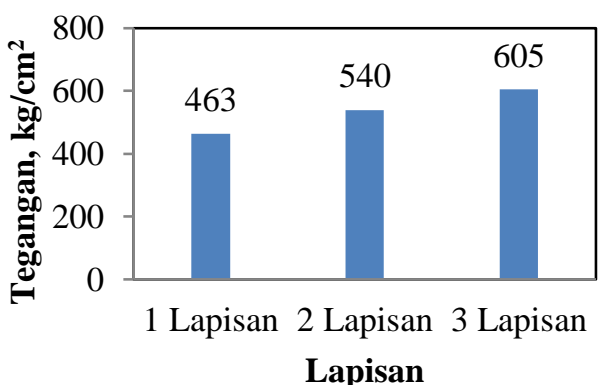

\section{Gambar 7. Grafik hubungan Tegangan Tarik Terhadap Variasi Lapisan Komposit}

Gambar 7 menunjukkan bahwa Tegangan Tarik terendah di dapat pada spesimen dengan 1 lapisan atas sebesar $463 \mathrm{~kg} / \mathrm{cm}^{2}$. Tegangan Tarik semakin tinggi seiring bertambahnya jumlah lapisan atas. Dalam hal ini komposit sandwich core styrofoam dengan 1 lapisan sudah bagus sebagai bahan pada model pesawat tanpa awak berdasarkan Tabel 4.3 (Nikhil V., Nayak, 2014). Pemilihan pada 1 lapisan atas juga diperkuat pada penelitian Andri Setiawan (2014) yang meneliti sifat mekanik pada polymetric composite foam yang di gunakan pada pesawat UAV (unmanned aerial vehicle) dengan tegangan tarik sebesar $62 \mathrm{~kg} / \mathrm{cm}^{2}$.

\section{Uji Bending}

Pengujian Bending juga di lakukan di Laboratorium Perancangan UNWAHAS. Pengujian di lakukan sebanyak 3 kali pada masing-masing spesimen. Rata-rata hasil pengujian Bending dapat dilihat pada Tabel 4

Tabel 4. Data Pengujian Bending

\begin{tabular}{lc}
\hline Lapisan & $\begin{array}{c}\text { Tegangan Bending } \\
\left(\mathbf{k g} / \mathbf{c m}^{2}\right)\end{array}$ \\
\hline 1 Lapisan & 491,7 \\
2 Lapisan & 559,8 \\
3 Lapisan & 702,7 \\
\hline
\end{tabular}

Pada Gambar 8 menunjukkan bahwa tegangan Bending terendah diperoleh pada spesimen dengan 1 lapisan atas yaitu sebesar $289,5 \mathrm{~kg} / \mathrm{cm}^{2}$. Semakin banyak jumlah lapisan semakin tinggi nilai tegangan Bending. Pada Pesawat Tanpa awak dengan bentang sayap 3-4 meter rata-rata mampu terbang pada kecepatan $80 \mathrm{Km} / \mathrm{jam}$ dan memiliki gaya angkat kurang lebih sebesar $29 \mathrm{~kg}$.

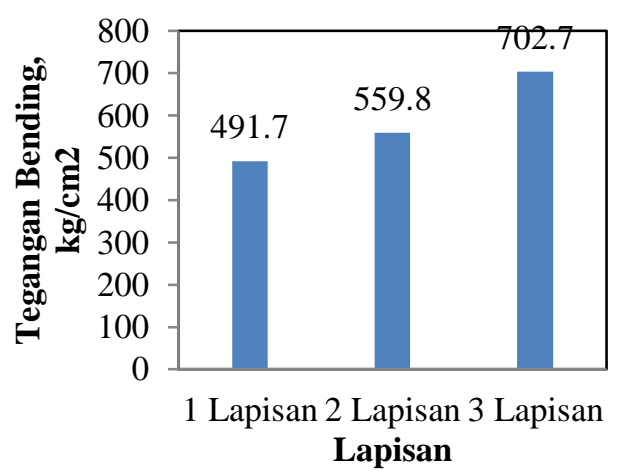

Gambar 8. Grafik Hubungan Tegangan Bending Terhadap Jumlah Lapisan Atas

Gaya angkat diperoleh dari perhitungan Lift pada sayap pesawat dengan rumus sebagai berikut: (Lennon, 1996)

$\mathrm{L}=1 / 2 \cdot \rho \cdot \mathrm{V}^{2} \cdot \mathrm{A} \cdot \mathrm{CL}$

Dengan Asumsi:

- Airfoil $=$ Clark Y

Airfoil

- Sudut Serang $=4^{0}(\mathrm{CL}=$ $0,75)$

- Ketinggian $=0$ feet terhadap permukaan air laut $(\sigma=$ 1)

- Kecepatan $\quad=22 \mathrm{~m} / \mathrm{s}$

- Luas Sayap $\quad=1,6 \mathrm{~m}^{2}$

Sehingga dapat di cari besaran gaya angkat ( Lift) sebagai berikut:

$$
\begin{aligned}
\mathrm{L} & =1 / 2 \times 1 \times 22^{2} \times 1.6 \times 0.75 \\
& =290 \mathrm{~N} \\
& =29 \mathrm{~kg}
\end{aligned}
$$

Dengan gaya angkat $29 \mathrm{~kg}$ maka diperkirakan 1 lapisan masih dapat mengangkat pesawat tanpa awak.

\section{Foto makro}

Foto makro yang disajikan adalah foto hasil patahan uji tarik. Lebih jelasnya disajikan pada Gambar 9. Pada foto makro yang di lakukan, ada perbedaan patahan antara ketiga spesimen yaitu pada spesimen 1 lapisan memiliki patahan yang sama pada lapisan atas dan bawah. Kemudian pada 2 lapisan atas dan 3 lapisan atas memiliki karakteristik patahan di mulai dari 1 lapisan bawah kemudian patahan disusul 2 lapisan atas dan 3 lapisan atas. Hal ini menunjukkan adanya 
perbedaan kekuatan antara lapisan bawah dan lapisan atas karena adanya variabel lapisan atas pada spesimen uji. Dan pada keseluruhan spesimen uji mengalami jenis patahan getas.

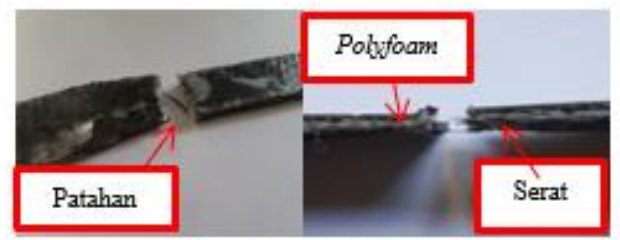

(a)

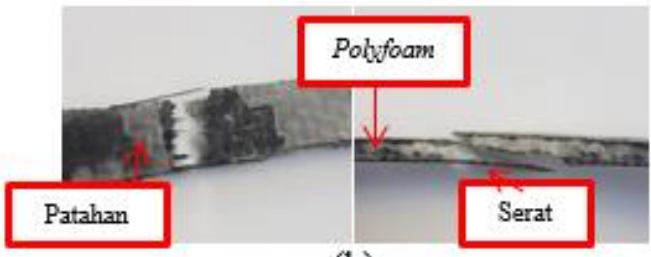

(b)

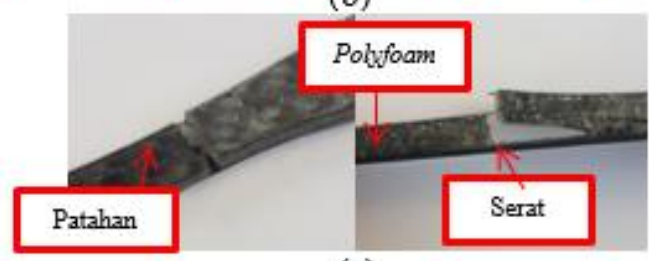

(c)

Gambar 9. Patahan 3 Lapisan Atas

\section{PEMILIHAN BAHAN}

Dalam pemilihan bahan pesawat tanpa awak ada beberapa kriteria bahan yang perlu diperhatikan. Kriteria bahan itu adalah efisiensi kekuatan statis (perbandingan kekuatan terhadap berat), serta biaya produksi material tersebut. Pemilihan bahan berdasar dari data-data pengujian Densitas, Uji Tarik, Uji Bending. Dalam hal ini spesimen dengan 1 lapisan atas menjadi pilihan karena memiliki berat yang paling ringan di antara 3 spesimen uji dan memiliki kekuatan yang memenuhi standar untuk Model Pesawat Tanpa Awak dengan bentang sayap 3-4 meter. Selain itu biaya pembuatan yang lebih murah pada spesimen 1 lapisan atas di banding spesimen 2 lapisan atas dan 3 lapisan atas.

\section{KESIMPULAN}

1. Massa jenis pada komposit karbon sandwich core styrofoam 1 lapisan atas, 2 lapisan atas, 3 lapisan atas secara berturut-turut 0,38 $\mathrm{g} / \mathrm{cm}^{2}, 0,40 \mathrm{~g} / \mathrm{cm}^{2}, 0,43 \mathrm{~g} / \mathrm{cm}^{2}$. Berat untuk body pesawat dengan bentang sayap 3 meter sebesar 1010 gram.

2. Pada pengujian tarik, nilai kekuatan tarik yang didapat dalam komposit karbon sandwich core styrofoam 1 lapisan atas, 2 lapisan atas,
3 lapisan atas secara berurutan sebesar 463 $\mathrm{kg} / \mathrm{cm}^{2}, 540 \mathrm{~kg} / \mathrm{cm}^{2}, 605 \mathrm{~kg} / \mathrm{cm}^{2}$. Sedangkan pada pengujian Bending nilai tegangan Bending yang didapat secara berurutan sebesar $289 \mathrm{~kg} / \mathrm{cm}^{2}, 330 \mathrm{~kg} / \mathrm{cm}^{2}, 393 \mathrm{~kg} / \mathrm{cm}^{2}$.

3. Dari foto makro disimpulkan bahwa ketiga spesimen mengalami patah getas namun memiliki perbedaan karakter patahan antar spesimen uji dikarenakan tidak imbangnya antara lapisan bawah dan lapisan atas.

4. Dari penelitian di atas untuk pemilihan bahan jatuh pada spesimen dengan 1 lapisan atas pada komposit karbon fiber core styrofoam yaitu dengan densitas $0,38 \mathrm{~g} / \mathrm{cm}^{2}$ dengan kekuatan tarik $463 \mathrm{~kg} / \mathrm{cm}^{2}$ dan kekuatan Bending sebesar $289 \mathrm{~kg} / \mathrm{cm}^{2}$.

\section{DAFTAR PUSTAKA}

ASTM, 2003, "Annual Book of ASTM Sandard", West Conshohocken,.

Lennon, A., 1996. Basic of R/C Model Aircraft Desight. USA: Air Age Media Inc.

Davis, Harmer E., Troxell, George Earl, Wiskocil, Clement T.. 1955. The testing and inspection of engineering material. New York: McGraw-Hill, Inc.

Hariyanto, A., 2007, Peningkatan Ketahanan Bending Komposit Hibrid Sandwich Serat Kenaf dan Serat Gelas Ber matrik Polyester Dengan Core Kayu Sengon Laut, Media Mesin, Vol.8 No.1, pp. 1 - 9

Irwanto, Respati, S. M. B., Purwanto, H., 2014, Analisis Kekuatan Tarik Dan Struktur Komposit Berpenguat Serat Alam Sebagai Bahan Alternative Pengganti Serat Kaca Untuk Pembuatan Dashboard, Jurnal Ilmiah Momentum Vol 10, No 2, hal $42-47$

Respati, S. M. B., Soenoko, R., Irawan, Y. S., Suprapto, W., Saputra, W. B., Purwanto, H., 2017, Capillary velocity of natural zeolite porous ceramic in different sintering temperatures, MM Science Journal, Issue: June, pp. 1803-1805

Nukhil V., Nayak, 2014, Composite Material in Aerospace Apalications, Internasional Journal of Scientific and Research Publication, Vol. 3, Issue 9, ISSN 22503153.

Wijoyo, Achmad N., 2014, Kajian Komprehensif Kekuatan Bending Komposit Sandwich Serat Aren-Polyester Dengan Core Gedebog Pohon Pisang, Jurnal Teknologi, Vol. 7, No. 4, Hal 128123. 